\title{
Effects of Aging on the Performance of Aggregates in Reclaimed Asphalt Pavement
}

\author{
Aftab Akbar ${ }^{1}$, Dr.Qaiser Iqbal ${ }^{2}$, Engr.Fazli-Karim ${ }^{3}$, Engr.Kashif Akbar ${ }^{4}$, \\ ${ }_{1,2,3,4}$ Sarhad University of Science \& Information Technology, Peshawar \\ engraftab123@gmail.com¹, qi.civil@suit,edu.pk², engr_fazli@yahoo.com³ ${ }^{3}$,engrkashif0@ hmail.com $^{4}$ \\ Received: 02 December, Revised: 12 December, Accepted: 18 December
}

\begin{abstract}
Maintenance and Overlay resolve medium distress, but reconstruction can be feasible and cost-effective because asphalt pavement deteriorated drastically with time and traffic. Therefore, pavements are required to be reconstructed or rehabilitated. Reuse of such construction waste is gaining popularity with the passage of time due to its benefits. The cost and shortage of virgin aggregate have encouraged the use of reclaimed asphalt pavement, and involved in regular practice in various countries around the world. Asphalt is $100 \%$ recyclable product in some states of US, but RAP usage has not yet been established in Pakistan. Therefore, in this research different percentages of aged aggregates are used in conjunction with virgin aggregates in asphalt mixtures. The virgin and RAP asphalt samples were then compared in terms of Marshall Stability, Rut resistance and indirect tensile strength (IDT). 22 samples including conventional and different RAP percentages were prepared for Marshall Stability, 10 samples for Rutting and 12 samples for IDT. It has concluded that the 60 percent RAP aggregate when used in conjunction with virgin aggregate in asphalt mixture gives improved Marshall Stability as compared to virgin aggregates when used in asphalt mixture, also the flow values of the 60 percent aged aggregate sample is neither open to rut of fatigue as compared to asphalt mixture prepared with virgin aggregate, and the indirect tensile strength of RAP mixture with $60 \%$ aged aggregate is high as compared to the asphalt mixture prepared with 100 percent virgin aggregates.
\end{abstract}

Keywords - Overlay,deteriorated,Asphalt pavement, stability, characterization, aggregate

\section{INTRODUCTION}

Composite materials such as concrete and asphalt concrete are components of aggregates; the aggregate serves as reinforcement to add strength to the overall composite material. Preferred bituminous aggregate sizes for road construction are given in (European Standard) EN 13043, EN 13242 for base layers of road construction and $\mathrm{EN} 13450$ for railway ballast. By volume, aggregate generally accounts for 92 to 96 percent of Bituminous concrete and about 70 to 80 percent of Portland cement concrete. Aggregate is also used for both elastic and rigid pavements. Aggregates can be naturally produced or manufactured. Extracted rock is typically reduced by mechanical crushing to accessible sizes. The aggregate are the central load bearing asphalt segment. Aggregates have different properties that are individually tested for the pavement construction with various types of tests.

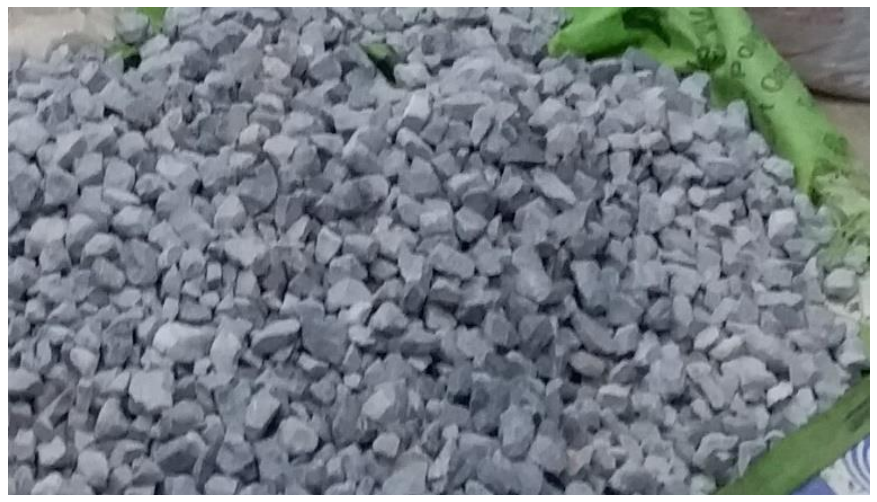

Fig:1 Margalla Aggregate

Classification by Shape of Aggregate

Rounded aggregates

Irregular/Partially rounded aggregates

Elongated aggregates

Angular aggregates

Flaky aggregates

Flaky and elongated aggregates

Classification by Size

1. Fine aggregate

2. Coarse aggregate

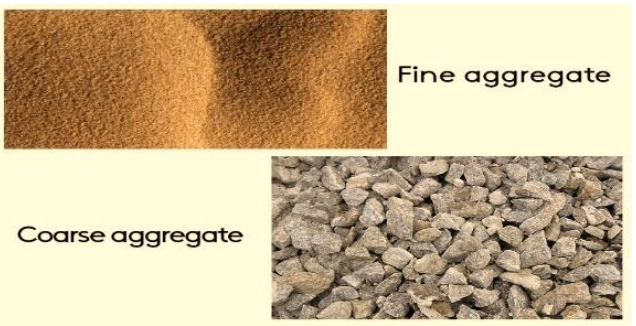

Fig:2 Fine and Coarse aggregate 
Desirable Properties of Road Aggregates

1. Strength

2. Durability

3. Toughness

4. Hardness

5. Shape of aggregates

6. Adhesion with bitumen

7. Shape of aggregates

8. Freedom from deleterious particle

\section{Strength}

The aggregates used in the construction of roads, the aggregates used in the wearing of the pavement should be particularly strong/ resistant enough to crushing to withstand the high stresses induced due to heavy traffic wheel loads.

\section{Hardness}

Due to moving traffic, the aggregates used in the surface are subject to constant rubbing or abrasion. Due to the presence of abrasive material such as sand, the abrasive action increasing between the tyres of vehicle and the aggregates exposed to the top surface. Thus, they should be stiff enough to resist the wear due to abrasive action of traffic.

\section{Toughness}

Aggregates in the pavement are also influenced by shifting loads of the wheel. The magnitude of impact increase with roughness of road and speed of vehicle. Severe impact is common when heavily loaded steel tired vehicles move on WBM. Another attractive feature of aggregates is the resistance to impact or hardness.

\section{Durability}

The aggregates are exposed to rains and ground water physical and chemical behavior, the impurities in them and that of atmosphere. It is therefore, desirable that the road stones used in the construction should sufficiently strong enough to withstand the weathering action. Soundness can be called as the property of aggregate to withstand the adverse weather behavior.

\section{Shape of Aggregate}

Aggregates can be rounded, flaky, angular, or elongated. Flaky and elongated particles have less strength than rounded and cubical particles. Thus, too flaky and too much elongated particles should be avoided.

\section{Adhesion with bitumen}

The aggregates in bituminous pavements should be less water-related relative to bitumen; otherwise in presence of water, the bituminous coating on the aggregates will be striped.

\section{Freedom from deleterious particle}

Aggregates requirements used in bituminous mixtures usually require clean aggregates, tough and durable in nature and free from excess amount of flat or elongated pieces, dust, clay balls and other objectionable material.
Aggregate Characterization

Aggregate Physical Properties

1. Maximum Aggregate Size

2. Gradation

3. Crushing

4. Abrasion

5. Toughness and Abrasion Resistance

6. Specific Gravity

7. Particle Shape and Surface Texture

8. Durability and Soundness

9. Cleanliness and Deleterious Materials

\section{A. Reclaimed Asphalt}

Large quantities of Reclaimed asphalt pavement (RAP) materials are produced during highway maintenance and construction. A part of this can be used in new hot mix asphalt concrete and rest is available for other uses. If these materials can be reused in the base and sub-base of the roads, the environmental impact will be minimized reduce and also transportation costs connected with road maintenance and construction activities. The properties of RAP materials can be improved by blending of aggregates and by addition of chemical stabilizers. In recent years there was a gradual increase in construction and demolition wastes. It has resulted in waste disposal problem due to shortage of available landfills. Reuse of these materials after proper recycling can be the right solution for the same. There will be a reduction in cost about 25 to $30 \%$ by reusing the recycled road aggregate generated at same site. Before using such materials the mechanical properties must be tested and suitable blending is done if required. Reclaimed asphalt pavement (RAP) materials and recycled concrete aggregate (RCA) are the most common recycled materials. The generation of RAP and RCA result in an aggregate of high quality and grading. Due to coating of asphalt on the aggregate of RAP it reduces the water absorption in aggregates.

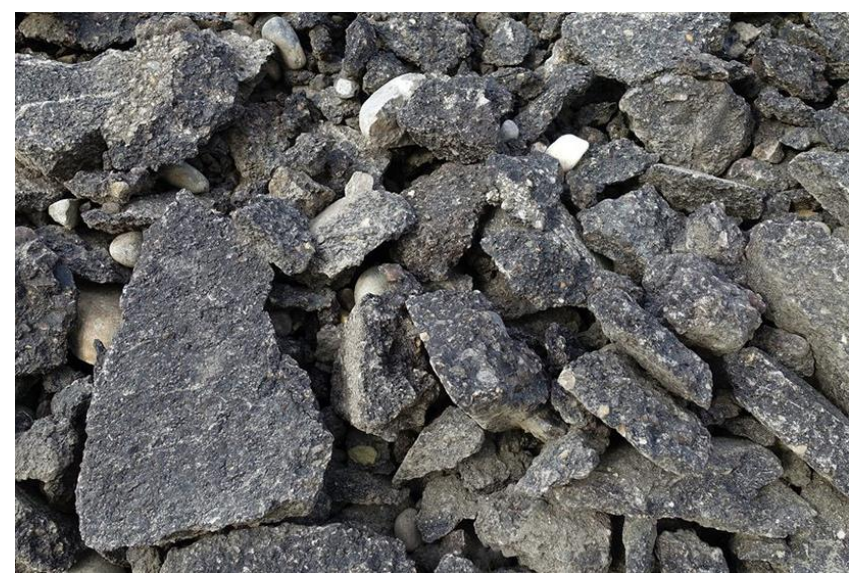

Fig: 3 Reclaimed Asphalt (GT Road site)

\section{B. Aging of Aggregates}

Asphalt binder properties change due to different factors. Asphalt binder aging is among the factors that caused shorter pavement service life. Aging adversely affects asphalt binder rheological properties causing deterioration in mixture 
performance. In the last decades, many tests were performed to evaluate the effects of aging on asphalt binder properties and asphalt mixtures. Also, many samples of the virgin, artificially aged and extracted asphalt binder were tested and comparative study between laboratory and field aging conditions were carried out. [1].

Asphalt aggregates are defined as the cumulative products o $\mathrm{f}$ breaking and sieving of asphalt (bituminous bound layers) fro $\mathrm{m}$ roads.Using these aggregates in new asphalt is a new way of saving economy and environment.But there are few points to consider before using these aggregates.

The repeated traffic on the road that can cause the properties of these aggregates to change.including changes in surface textur e, aggregate form and breakage due to heavy loads. The salt wat er under the soil also has an impact on the aggregates by enteri ng aggregates.Continuous freezing and thawing, causing aggregate cracks and unstable road conditions.

In Hot Mixed Asphalt pavements, RAP was used in different percentages, often reaching upto 80 percent, and typically from 20-50\% [2] In this study sample of Reclaimed asphalt pavement (RAP) aggregate materials were collected and analyzed for suitability of their usage in flexible pavements. Their characteristics including gradation, California Bearing Ratio (C.B.R).Aggregate Impact value, Aggregate Crushing value, Specific gravity, Flakiness \& Elongation Index, Loss Angles Abrasion value, Water absorption and soundness were determined and compared to the MORTH specifications [3].

Bitumen is a very high viscosity liquid or solid consisting mainly of mineral oil (containing a set of high molecular weigh thydrocarbons asphaltic in nature and very no oxygen, sulphur and nitrogen. Hydrocarbon derivatives (such as Asphaltenes, M altenes) soluble in carbon disulphide and are nonvolatile and $\mathrm{m}$ ollify continuously when warming up.It depends on the derivati ve mode; it is either brown or black in colour, has waterproofin $\mathrm{g}$ and sticking properties and has uneven hardness and instabilit y.Asphaltenes play a vital role in the hydrocarbon's normal elastic nature, which is primarily responsible for elasticity and rigidity. [4]

Temperature with more effect on Flexible pavement softens the road when the temperature is high and when the temperatu re is low appears to crack.In addition, heavy traffic and high lo ading vehicles preregularly deflect roads and cause repair and maintenance costs. Therefore, to obtain these characteristics, it i $\mathrm{s}$ important to boost the standard asphalt by the product that ca $\mathrm{n}$ play the role as binder.[5]

Asphalt binder properties change due to different factors. Asphalt binder aging is among the factors that caused shorter pavement service life. Aging adversely affects asphalt binder rheological properties causing deterioration in mixture performance. In the last decades, many tests were performed to evaluate the effects of aging on asphalt binder properties and asphalt mixtures. Currently, due to the end up of its design life and traffic loads, asphalt pavements may badly deteriorate. The reconstruction of the pavement may become an economical and feasible solution. Reconstruction of a pavement requires removal of pavement surfaces. Waste asphalt removed from a failed pavement surface is a mixture of aggregate coated with bitumen and is collected from failed asphalt pavement surfaces and has been used as flexible layer construction material for more than 30 years. The use of reclaimed material considerably saves material, money and energy, without compromising the strength. Its importance rises in the light of increasing cost of bitumen, scarcity of good quality aggregate and priority towards the preservation of environment. Recycled aggregates are the materials of future. This sustainable practice is an effective means of pavement rehabilitation as the materials which have reached the end of their service life are still made valuable. In Europe and US, studies have concluded that $80 \%$ of the recycled material is used in construction of roads. However, the quality of the pavement constructed depends on the origin, variability, stocking and production conditions of the reclaimed material. The strength of the reclaimed material can be improved through the use of rejuvenators. Considering the material and construction cost alone it is estimated that using recycled materials, saving ranging from $14 \%-34 \%$ can be achieved. Hence bituminous pavements using reclaimed aggregates can evolve into a regular practice for sustainable construction.

\section{Sources of Reclaimed Aggregates}

The use of reclaimed materials enables to improve the quality of infrastructure in sustainableways. This includes reclaiming aggregates and rejuvenating their component parts for use in new pavements. The two major sources to obtain them are 1-Construction \& Demolition waste (CDW) and 2-Reclaimed Asphalt from old pavements (RAP).

The strength of concrete is dependent on size, shape, grading, surface texture mineralogy of the aggregate, strength, stiffness [6] suggested that the effect of aggregate strength on the compressive strength of concrete is not considered in the case of normal-strength concrete, as it is much stronger than the transition zone and cement paste matrix. [6] also explained that the transition zone and the cement paste matrix would fail before the aggregate and thus nullify the effect of the strength of aggregate. The aggregate strength is usually not a factor in normal strength concrete as the failure is generally determined by the cement paste- aggregate bond. Much research has linked the bonding of the aggregate to the strength of concrete [7].

Greater aggregate surface areas result in better bonding between the aggregate and the cement paste. They also observed that rough aggregates tend to exhibit better binding than smooth aggregates. [8]

They also noticed that rough aggregates appeared to be more binding than smooth aggregates. [9] made similar observations as [10] but linked the surface properties to the cracking stress suggesting rough aggregates would crack at a higher stress compared to smooth aggregates, compressive strength can be seen to decreases with an increase in maximum coarse aggregate size particularly for concretes with low water-cement ratios.

The Federal Highway Administration estimated that in US, 73 of the 91 million metric tons of asphalt pavements were removed every year during resurfacing and widening projects and are reused as part of new roads, roadbeds, shoulders and embankments. [11]. The use of Reclaimed asphalt also minimizes the cost of transportation. (Dr. Soosan et al.2016). Some technical operations are somehow required when reclaimed aggregates are used in asphalt mixtures. Some 
environmental, energy and cost benefits are considered to be achieved, as well as the mechanical performance. [12]

The utility of the road is impaired by the pathologies generated by the aging process, various research studies should be carried out with the idea of decreasing the effects of this phenomena, in order to have a greater sense of comfort and security when using this infrastructure. [13]. The usual statement damage caused by moisture is consistent loss of adherence and loss of cohesion in the mixture between the aggregate and bitumen and loss of adherence to the aggregate-asphalt or cohesion within the bulk mastic [14].

The Marshall approach was used to test the performance evaluation of asphalt mixtures with various Reclaimed asphalt pavement ratios. The wearing course mixtures with 20, 40, 60, 80 and $100 \%$ RAP content were made and then compare it with the control design (No RAP content). The Research purpose is to design good wearing surface with high RAP content without sacrificing quality. [15].

\section{Objectives:}

1. To check the performance of RAP aggregates in reclaimed asphalt pavement and compare it with the performance of Virgin aggregates used in conventional asphalt mixture.

2. To suggest the procedure to reuse the Recycle aggregates by suggesting the percentage addition of Fresh aggregates in order to restore its design properties.

\section{MethodOLOGY}

\section{A. Materials}

The bitumen used in this test was of penetration grade 60/70 brought from Attock Refinery. The course aggregate used in preparation of samples are 3/4" (inch) downgraded and were brought from Margalla. Sieve analysis was done in university.The RAP is collected from site of G.T road. Benzene or CTC is used for Extraction Purpose.
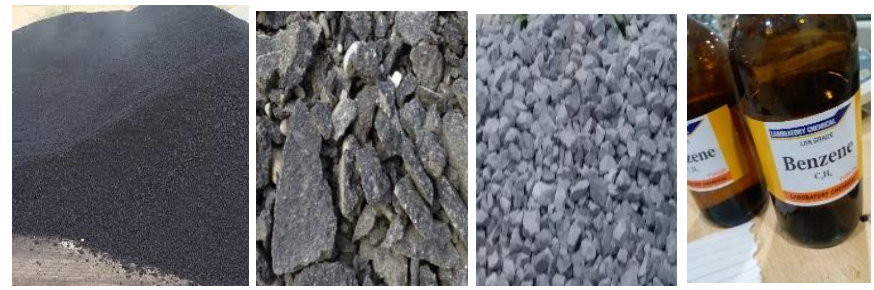

Fig: 4 Showing Asphalt, RAP, Aggregates, Benzene

\section{B. Tests performed}

\section{1) Sieve Analysis (Gradation):}

A sieve analysis (gradation test) is a common practice or technique in civil engineering for testing particle size distribution (also called gradation) of a granular material.

\section{2) LOS Angeles Abrasion Test}

The Los Angeles test is a measure of degradation of mineral aggregates of standard grading's resulting from a combination of actions including abrasion or attrition, impact, and grinding in a rotating steel drum containing a specified number of steel spheres. The Los Angeles abrasion test is a common test method used to indicate aggregate toughness and abrasion characteristics

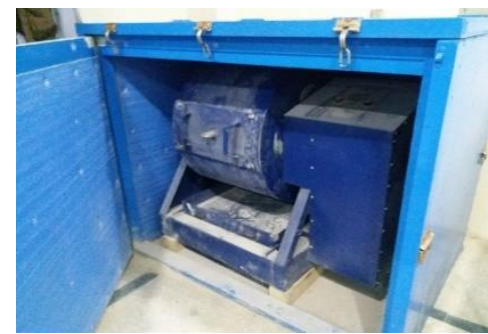

Fig: 5 Los Angeles Abrasion Testing

\section{3) Water Absorption Test}

Water absorption gives an idea of strength of aggregate. Aggregates having more Water absorption are more porous in nature and generally considered unsuitable unless they are found to be acceptable based on strength impact and hardness test.

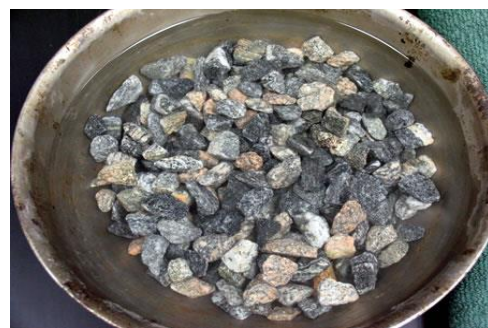

Fig:6 Water Absorption Test

\section{4) Crushing test}

Aggregate crushing test on coarse aggregates offers a relative measure of aggregate crushing resistance under a progressive compressive load. Coarse aggregate crushing value is the percentage by weight of the crushed material obtained when test aggregates are subjected to a specified load under standardized conditions

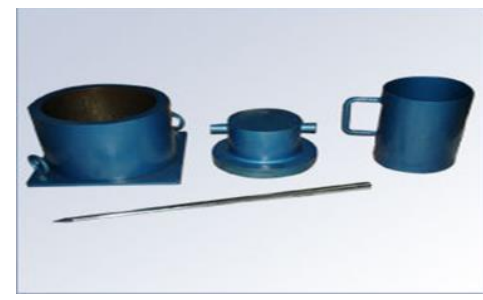

Fig: 7 Crushing Test Apparatus

\section{5) Impact test}

The aggregate impact test is conducted out to determine the resistance to impact of aggregates

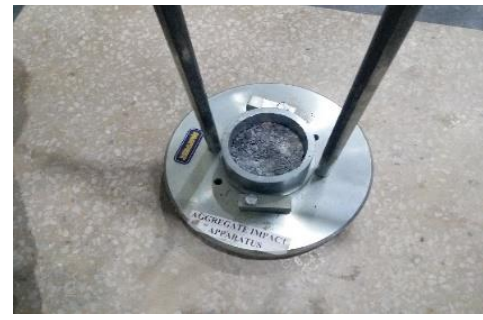

Fig:8 Performing Impact test 
6) Soundness test

Soundness test is intended to study the resistance of aggregates to weathering action, by conducting accelerated weathering test cycle

\section{7) Shape tests}

The particle shape of the aggregate mass is determined by the percentage of flaky and elongated particles in it.

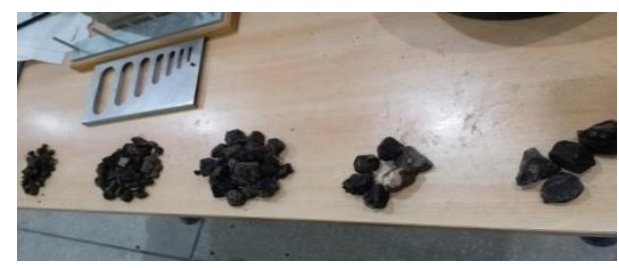

Fig:9 Shape Testing for pavement works

III. RESULTS AND EXPERIMENTAL WORK

Table:1 Laboratory Results on Aggregate

\begin{tabular}{|c|c|c|c|c|}
\hline 或淟 & 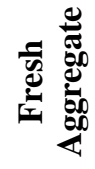 & 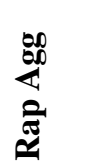 & 莺 & 总 \\
\hline $\begin{array}{l}\text { LOS } \\
\text { Angeles } \\
\text { abrasion } \\
\text { test }\end{array}$ & $\begin{array}{l}11.2 \\
\%\end{array}$ & $18 \%$ & $\begin{array}{l}\text { Max permissible } \\
\text { Value }=30 \%\end{array}$ & $\begin{array}{l}\text { ASTM } \\
\text { C-131 }\end{array}$ \\
\hline $\begin{array}{l}\text { Water } \\
\text { absorption } \\
\text { test }\end{array}$ & $\begin{array}{l}0.88 \\
\%\end{array}$ & $1.24 \%$ & $\begin{array}{l}\text { Ranges from } 0.1 \\
\text { to } 2.0 \%\end{array}$ & D-570-98 \\
\hline $\begin{array}{l}\text { Impact } \\
\text { test }\end{array}$ & $\begin{array}{l}5.105 \\
\%\end{array}$ & 6.715 & $\begin{array}{l}10-20 \%=\text { Strong } \\
20-30 \%= \\
\text { Satisfactory }\end{array}$ & $\begin{array}{l}\text { ASTM E- } \\
2248-18\end{array}$ \\
\hline $\begin{array}{l}\text { Crushing } \\
\text { test }\end{array}$ & $\begin{array}{l}17.5 \\
\%\end{array}$ & $20.2 \%$ & $\begin{array}{l}\text { For Bituminous } \\
\text { Surface } \\
\text { dressing }=30\end{array}$ & $\begin{array}{l}\text { ASTM C- } \\
39\end{array}$ \\
\hline $\begin{array}{l}\text { Soundness } \\
\text { test }\end{array}$ & 18 & 12 & $\begin{array}{l}\text { Should not be } \\
\text { more than } 25 \% \\
\text { with } \\
\mathrm{Na} 2 \mathrm{~s} 04 \text { (Sodium } \\
\text { Sulphate) }\end{array}$ & $\begin{array}{l}\text { ASTM } \\
\text { C- } 88\end{array}$ \\
\hline $\begin{array}{c}\text { Flakines, } \\
\text { Elongatio } \\
\mathrm{n}\end{array}$ & $\begin{array}{c}22.5 \\
\%\end{array}$ & 26.8 & $\begin{array}{c}\text { Flakiness \& } \\
\text { Elongation test } \\
\text { are not } \\
\text { applicable to } \\
\text { Aggregate sizes } \\
\text { smaller than } \\
6.33 \mathrm{~mm}\end{array}$ & $\begin{array}{l}\text { ASTM-D } \\
7491\end{array}$ \\
\hline $\begin{array}{l}\text { Specific } \\
\text { Gravity }\end{array}$ & 2.89 & 2.62 & $\begin{array}{l}\text { Ranges from } 2.5 \\
\text { to } 3.0\end{array}$ & $\begin{array}{l}\text { ASTM C- } \\
127\end{array}$ \\
\hline
\end{tabular}

Table:2 Marshall Parameter for Conventional Mix

\begin{tabular}{|c|c|c|c|c|c|c|c|}
\hline 窇 & $\stackrel{8}{2}$ & $\sum_{i}^{\mathbb{S}}{ }^{\circ}$ & $\mathbb{x}_{\infty}^{\mathbb{2}}$ & है & 离 & 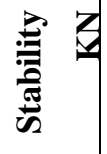 & $\stackrel{\Xi}{\Xi}$ \\
\hline $\begin{array}{l}3 . \\
5\end{array}$ & 6.42 & 13.95 & 52.55 & 2.32 & 2.56 & 14.1 & 9.08 \\
\hline 4 & 5.10 & 13.10 & 61.12 & 2.34 & 2.76 & 14.4 & 8.89 \\
\hline $\begin{array}{l}4 . \\
5\end{array}$ & 4.12 & 12.95 & 68.20 & 2.36 & 2.39 & 14.4 & 8.87 \\
\hline 5 & 3.12 & 13.8 & 72.12 & 2.38 & 2.46 & 13.7 & 9.31 \\
\hline $\begin{array}{l}5 . \\
5\end{array}$ & 2.81 & 14.25 & 76.80 & 2.34 & 2.49 & 12.9 & 9.79 \\
\hline
\end{tabular}

Following graphs is based on Conventional data of the above table.

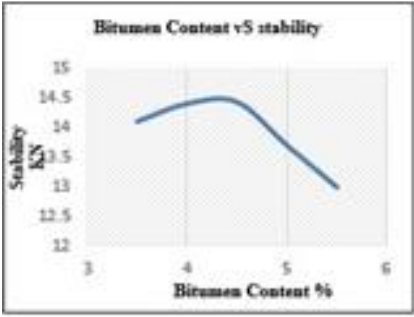

Fig 10: B.C Vs Stability

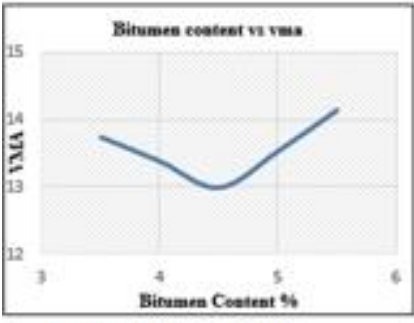

Fig 12: B.C Vs VMA

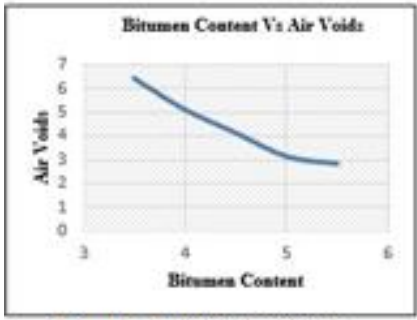

Fig 14: B.C Vs Air Voids

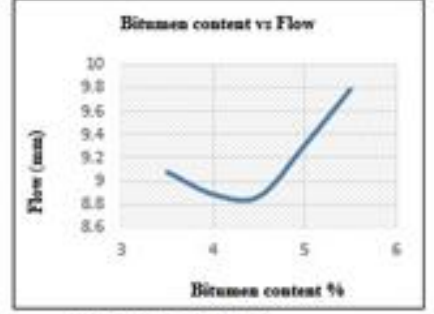

Fig 11: B.C Vs Flow

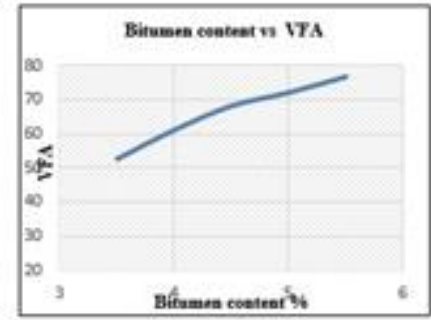

Fig 13: B.C Vs VFA

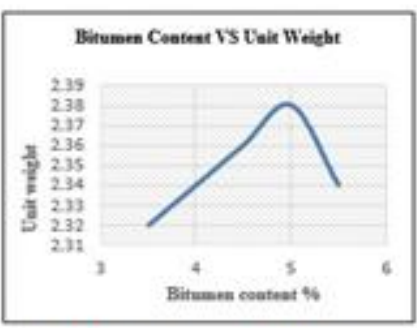

Fig 15: B.C Vs Unit Wt.
The optimum binder content for the following specimens are O.B.C $=4.4$, Samples with percentage of RAP Aggregate Mixed 
Table:3 Results of Different \% of RAP used in Samples

\begin{tabular}{|c|c|c|c|c|c|c|c|}
\hline$\frac{2}{2}$ & $\overleftrightarrow{>} 0^{\circ}$ & $\sum_{>}^{\mathbb{I}} d^{0}$ & $\sum_{>}^{\mathbb{J}} 0^{0}$ & छ & हี & 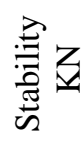 & 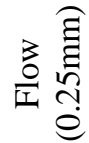 \\
\hline 0 & 3.80 & 69.50 & 12.99 & 2.42 & 2.39 & 15.9 & 10.95 \\
\hline 20 & 3.66 & 74.37 & 14.29 & 2.33 & 2.42 & 13.9 & 12.35 \\
\hline 40 & 5.47 & 66.72 & 16.45 & 2.28 & 2.41 & 14.1 & 12.15 \\
\hline 60 & 4.01 & 77.01 & 18.78 & 2.23 & 2.36 & 15.5 & 10.91 \\
\hline 80 & 2.86 & 77.18 & 12.53 & 2.41 & 2.48 & 10.4 & 14.49 \\
\hline $\begin{array}{c}10 \\
0\end{array}$ & 2.55 & 80.35 & 13.31 & 2.40 & 2.47 & 9.15 & 16.31 \\
\hline
\end{tabular}

Following Graphs are based on Different \% RAP Agg Data in the above table.

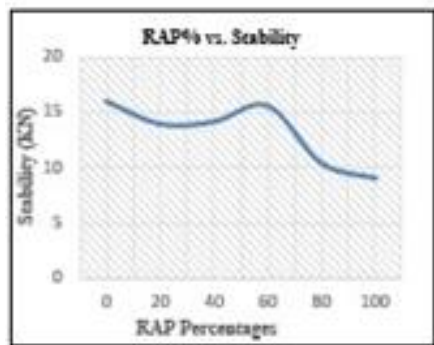

Fig 16: RAP \% Vs Stability

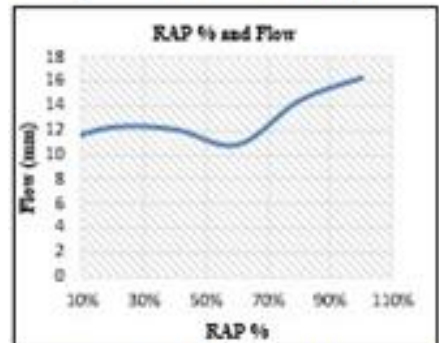

Fig 18: RAP \% Vs VMA

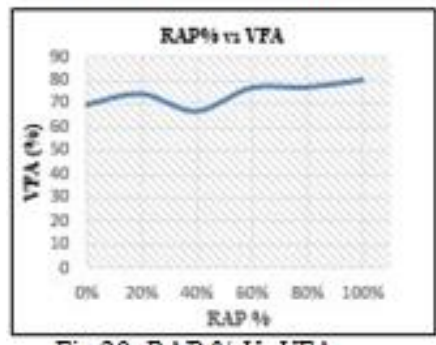

Fig 20: RAP \% V VFA

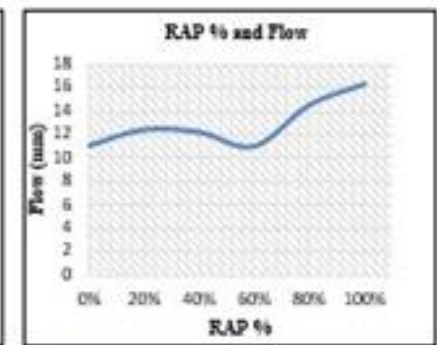

Fig 17: RAP \% Vs Flow

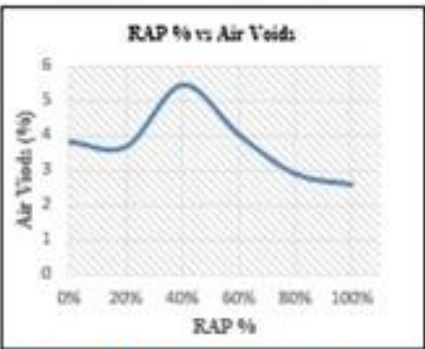

Fig 19: RAP \% Vs Air Voids

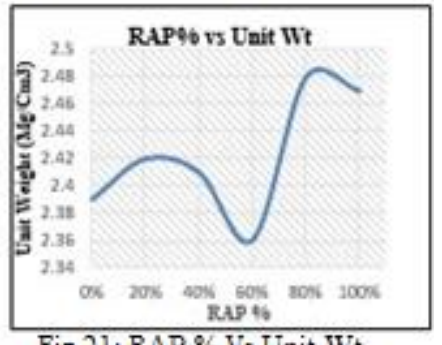

Fig 21: RAP \% Vs Unit Wt.

\section{Rutting test}

This table and graph shows shows No. of passes Vs rutting, and as highlited in different colors.

Table:4 Showing No. of Passes Vs Rut Depth

\begin{tabular}{|c|c|c|c|c|c|c|}
\hline $\begin{array}{l}\text { No. of } \\
\text { Passes }\end{array}$ & $\begin{array}{l}\text { Rut } \\
\text { depth } \\
0 \\
\%\end{array}$ & $\begin{array}{l}\text { Rut } \\
\text { depth } \\
20 \\
\%\end{array}$ & $\begin{array}{l}\begin{array}{l}\text { Rut } \\
\text { depth }\end{array} \\
40 \\
\%\end{array}$ & $\begin{array}{l}\text { Rut } \\
\text { deph } \\
60 \\
\%\end{array}$ & $\begin{array}{l}\text { Rut } \\
\text { depth } \\
80 \\
\%\end{array}$ & $\begin{array}{l}\begin{array}{l}\text { Rut } \\
\text { depth }\end{array} \\
100 \\
\%\end{array}$ \\
\hline 1000 & -0.62 & -1.01 & -0.69 & -0.97 & -1.1 & -1.9 \\
\hline 2000 & -1.26 & -2.3 & -1.9 & -1.25 & -2.45 & -3.19 \\
\hline 3000 & -1.99 & -3.4 & -2.68 & -1.99 & -3.21 & -4.95 \\
\hline 4000 & -2.62 & -4.09 & -3.66 & -2.65 & -4.4 & -6.59 \\
\hline 5000 & -2.99 & -5.22 & -4.29 & -2.98 & -5.52 & -7.95 \\
\hline 6000 & -3.45 & -6.17 & -4.82 & -3.10 & -6.89 & -8.86 \\
\hline 7000 & -3.86 & -7.05 & -5.65 & -3.42 & -8.2 & -9.99 \\
\hline 8000 & -4.25 & -7.81 & -5.99 & -3.66 & -8.56 & -10.56 \\
\hline 9000 & -4.62 & -8.97 & -6.45 & -3.72 & -8.85 & -10.75 \\
\hline 10000 & -4.82 & -8.97 & -6.59 & -3.73 & -8.86 & -10.74 \\
\hline
\end{tabular}

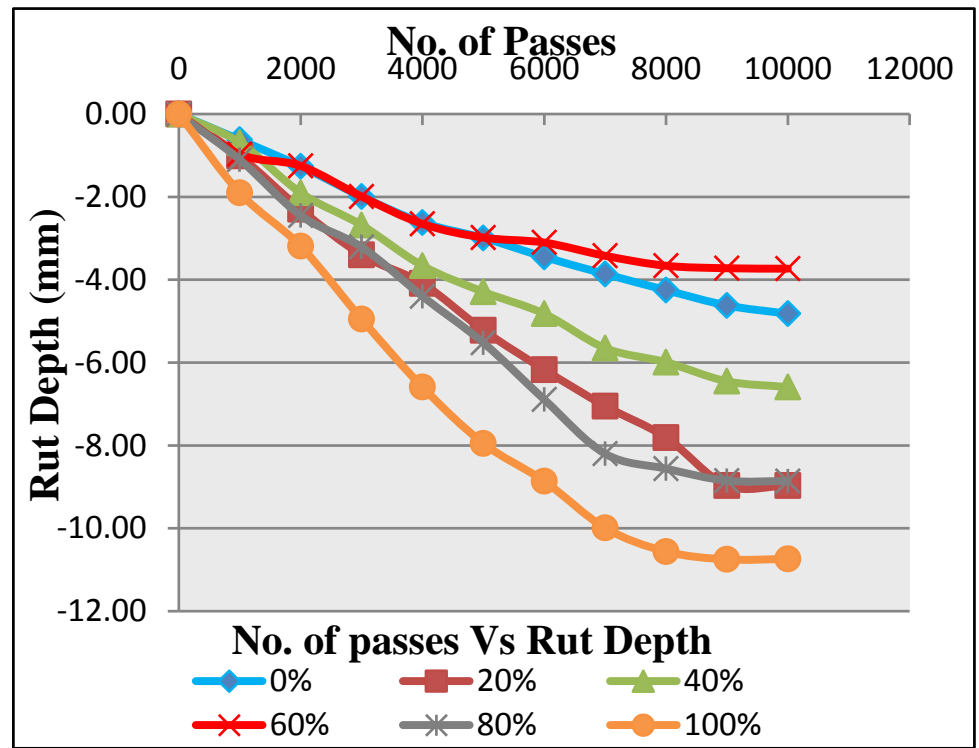

Fig 22: Showing No. of Passes Vs Rut Depth

Result of Indirect Tensile Strength

The values of IDT strength may be used to evaluate the relative quality of asphalt mixtures in conjunction with laboratory mix design testing and for estimating the potential for rutting or cracking. The results can also be used to determine the potential for field pavement moisture damage when results are obtained on both moisture-conditioned and unconditioned specimens. 
Table: 5 Indirect Tensile Strength

\begin{tabular}{|c|c|c|c|}
\hline \multirow[t]{2}{*}{ S.No } & \multirow{2}{*}{$\begin{array}{c}\begin{array}{c}\text { Mixture } \\
\text { Type } \\
\text { (MPa) }\end{array} \\
\text { Percentages }\end{array}$} & \multicolumn{2}{|c|}{$\begin{array}{c}\text { IDT Strength (MPa) } \\
\qquad \mathrm{t}=\frac{2 p}{\lambda \mathrm{tD}}\end{array}$} \\
\hline & & $\begin{array}{c}\text { Before } \\
\text { Freezing }\end{array}$ & $\begin{array}{c}\text { After } \\
\text { freezing }\end{array}$ \\
\hline 1 & 0 & 516 & 370 \\
\hline 2 & 20 & 465.60 & 305.10 \\
\hline 3 & 40 & 431.84 & 245.40 \\
\hline 4 & 60 & 501.92 & 358.25 \\
\hline 5 & 80 & 382.88 & 252.78 \\
\hline 6 & 100 & 261.14 & 172.61 \\
\hline
\end{tabular}

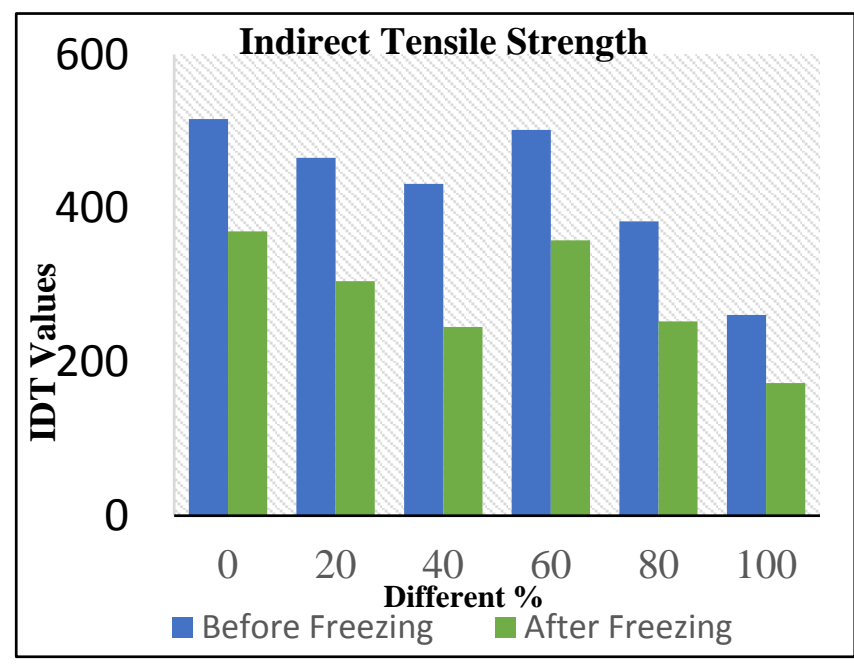

Fig 23: Different \% of RAP Vs. IDT Values

\section{CONFLICT OF INTEREST}

I declare that there is no conflict of interest and the previous work of the original author has been properly cited.

\section{CONCUSLION}

In this research, different percentages of aged aggregates were used in combination with virgin aggregates in asphalt mixtures. The virgin and reclaimed asphalt pavement (RAP) samples were then compared in terms of Marshall Stability, Rut resistance and indirect tensile strength (IDT) of asphalt. Twenty two (22) samples prepared for Marshall Stability, Ten samples for rut resistance and twelve samples were prepared for indirect tensile strength.

1. The $60 \%$ RAP aggregates when used in conjunction with virgin aggregates it was established that the stability values were higher for mixtures made with aged asphalts as compared to virgin aggregates when used in asphalt mixture.
2. The flow values of the RAP prepared with $60 \%$ shows that aged aggregate is neither open to rut nor fatigue as compared to asphalt mixture prepared with virgin aggregate.

3. The Rut resistance of the $60 \%$ RAP is maximum at 10,000 passes as compared to the virgin and other percentages of RAP aggregates when used in asphalt mixtures.

4. The indirect tensile strength of RAP mixture with $60 \%$ aged aggregate is high as compared to the asphalt mixture prepared with 100 percent virgin aggregates.

\section{RECOMMENDATIONS}

1. On the basis of the results given above, it is recommended that using $60 \%$ of RAP aggregates in new asphalt pavement can give better result.

2. Road pavement will get more strengthen when RAP aggregates is used in $60 \%$ ratio.

3. It will be more stable and will neither open to rut nor fatigue $\&$ will give better result than new pavement.

4. It can also minimize the construction cost and keep the environment clean.

\section{REFERENCES}

[1] Kheiralipour, Kamran, and Soraya Hoseinpour. "Determining and Modeling Shearing Properties of Peppermint Stem." Caspian Journal of Applied Sciences Research 5.3 (2016).

[2] Hussain, Arshad, and Qiu Yanjun. "Evaluation of asphalt mixes containing reclaimed asphalt pavement for wearing courses." Proceedings. International Conference on Traffic and Transportation Engineering, School of Civil Engineering, Southwest Jiaotong University, Chengdu, China, IPCSIT. Vol. 26. 2012.

[3] Mishra, Brajesh. "A Study on Characteristics of Subgrade Soil by Use of Foundry Sand and Iron Turnings."

[4] McDaniel, R.S., Soleymani, H., and Slah, A. (2002). Use of Reclaimed Asphalt (RAP) under Superpave Specifications, Report No. FHWA/IN/JTRP-2002/6, North Central Superpave Center, West Lafayette, IN, USA.

[5] McDaniel, R.S., Soleymani, H., Anderson, R.M., Turner, P., and Peterson, R. (2000). Incorporation of Reclaimed Asphalt Pavement in the Superpave System, NCHRP 9-12, National Cooperative Highway Research Program, Transportation Research Board.

[6] Nilsen, A. Ulrik, and Paulo JM Monteiro. "Concrete: a three phase material." Cement and Concrete Research 23.1 (1993): 147-151.

[7] Kosmatka, Steven H., Beatrix Kerkhoff, and William C. Panarese. Design and control of concrete mixtures. Vol. 5420. Skokie, IL: Portland Cement Association, 2002.

[8] Neville, Adam M., and Jeffrey John Brooks. Concrete technology. England: Longman Scientific \& Technical, 1987.

[9] Jones, R., and MFi Kaplan. "The effect of coarse aggregate on the mode of failure of concrete in compression and flexure." Magazine of Concrete Research 9.26 (1957): 89-94.

[10] Neville, Adam M., and Jeffrey John Brooks. Concrete technology. England: Longman Scientific \& Technical, 1987.

[11] Abdelhak, Bordjiba, et al. "Effect of recycled asphalt aggregates on the rutting of bituminous concrete in the presence of additive." Arabian Journal for Science and Engineering 41.10 (2016): 4139-4145.

[12] Handbook, Median. "Florida Department of Transportation." Tallahassee, FL (1997). 
[13] Higuera Sandoval, Carlos Hernando, Xiomara Vanessa Camargo Amaya, and Edwin Alexander Suárez Molano. "Effect of Aging on the Properties of Asphalt and Asphalt Mixtures." Ingeniería y Universidad 19.2 (2015): 335-349.

[14] Caro, Silvia, et al. "Moisture susceptibility of asphalt mixtures, Part 1: mechanisms." International Journal of Pavement Engineering 9.2 (2008): 81-98.

[15] Hussain, Arshad, and Qiu Yanjun. "Evaluation of asphalt mixes containing reclaimed asphalt pavement for wearing courses." Proceedings. International Conference on Traffic and Transportation Engineering, School of Civil Engineering, Southwest Jiaotong University, Chengdu, China, IPCSIT. Vol. 26. 2012.

[16] Mehta, P. Kumar, and P. J. M. Monteiro. "Durability." P. K. Mehta.-Concrete, microstructure, properties and materials.--Westerville: JP Skalny (Ed) (1993): 113-155

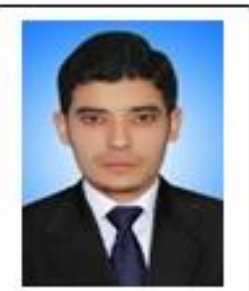

Aftab Akbar is the resident of Khyber Pakhtunkhwa,Peshawar-Pakistan, $\mathrm{He}$ did his bachelors in civil engineering from Sarhad university of science and technology Peshawar and persuing Master in Transportation Engg from the same Institution (SUIT). The paper is the Resarch project for Master's Degree. 